\title{
Beyond visual literacy: Communication design as a cultural mediation process
}

\author{
Alfredo Calosci \\ Università degli Studi di Sassari, Dipartimento di Architettura Design \\ e Urbanistica, Alghero, Italia \\ \{alfredoc\}@negot.net
}

\begin{abstract}
This paper will present a modest theoretical contribution, from an historical perspective, trying to underline the fact that our knowledge on visual communication has deep roots in fields that reside under the domain of others non visual disciplines. By doing so, we hope that this short jump into the past may result useful to face contemporary communication challenges.
\end{abstract}

Keywords: Rhetoric / Perception / Ancient Schematic Representations / Cognition / Transmedia

\section{A multidisciplinary scenario}

One of the reason why we visualize is because we believe an image can stand for a thousand words. As matter of facts we all know that the relations between words and images - as well as diagrams, notations, monograms and all kind of forms of marks are much more complex as they constantly interacts in our communication systems (Ong 2002, Perondi 2012).

Diagrams - as well as others spatial configuration of signs - have proved to be incredibly efficient due to their ability to create memorable mental images of complex systems. For this reason they have been widely adopted to convey knowledge, no matter if based on "scientific evidences" rather than "facts" or "faith".

As visually literate people most communication designers are familiar with ancient schematic representations (Anceschi 1992) as trees, wheels, stairs and even with more complex visual metaphors like the "tower of knowledge", the "lignum vitae" or the "six winged seraph".

This paper will present a modest theoretical contribution, from an historical perspective, trying to underline the fact that our knowledge on visual communication has deep roots in fields that reside under the domain of others non visual disciplines. By doing so, we hope that this short jump into the past may result useful to face contemporary communication challenges.

Data visualization is not just about images - as proof of facts many of the historical (and more recent) contributions to this specific form of communication 
have been introduced by unorthodox designers. Most of the manuals on data visualization mentions historical examples likes the 1854 (Physician) John Snow London cholera map or (Nurse) Florence Nightingale's Diagram of the Causes of Mortality in the Army of the East, as well as (Civil Engineer) Charles Joseph Minard's work or (Geographer) Jacques Bertin contributions.

This multidisciplinary scenario is not just about professionals from different fields occasionally producing images; as the Isotype experience demonstrates, data visualisation is often part of a much more complex transmedia strategy where the visual abilities may have a prominent, but not necessary leading, role. As Marie Neurath and Robin Kinross pointed out (Neurath, Kinross 2009) the Isotype method was much more than a simple matter of symbols and pictograms, it represented a multidisciplinary approach for transforming information into a visual form. The graphic work of Gerard Arntz, Marie Neurath and others visual designers became the basis of a versatile syntax, that included also verbal elements, in order to produce visual explanations for a wide range of audience through publications, exhibit design and even a few motion graphics.

\section{A web of images}

The starting point of this contribution is about public speeches that includes also some visual elements and is based on an essay written by a professor of Italian Literature at the Scuola Normale Superiore in Pisa. By studying the beginning of vernacular preaching, Lina Bolzoni (2004) shows the use of a wide web of images as part of what we may call today a transmedia strategy of communication from the early XIV century. Thanks to her knowledge of rhetoric, and the role of images in several mnemonic techniques, the author unveils a dense network of meaning as it was supposed to be perceived at the time of their creation. Because, even for visually literate people, there are images we are no longer able to see, although we look at them.

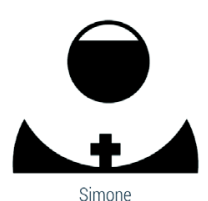

Simone

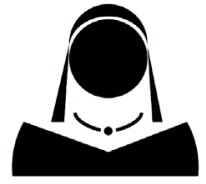

Caterina

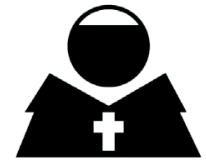

the young friar

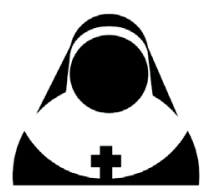

young nun

Fig. 1. Colloquio Spirituale: the four characters.

Part of this particular journey across the vernacular preaching, from its origins to St. Bernardino da Siena, is dedicated to the "Colloquio Spirituale" (spiritual conversation), a sermon written by Simone da Cascina by the end of the XIV century. The text is a dialog among four characters - two males and two females, two young 
and two old - each one absolving a precise narrative role. The two main characters are, from one side, Simone: the theologist, the main teacher, the one who knows and is trying to explain all the deep meaning of the liturgy - and, on the other side, Caterina: the religious woman who is willing to know and the one who arise questions. Along the conversation they are joined, in first place, by a young friar and shortly later by a young noun. The four together covers all the main functions that rhetoric prescribes for an effective and compelling discourse: to teach, to amuse and to move (docere, delectare, movere) and, in a way, they represent them in a kind of teatral allegory.

Simone and Caterina are in charge of the docere part of the discourse in a sequence of questions and answers interrupted, every once y a while, by the interventions of the young friar - who rephrases Simone's answers in visual metaphors. Most of the these allegories represents spaces and building - and others kind of locis - amusing the reader and offering him places to hang concepts in memory. While doing so the young friar get an immediate enthusiastic feedback from the young noun who get enlightened by the metaphors and moved by the acquired knowledge.

Shaped in this way, the conversation can stimulates the intellect, the will and the memory of the reader by offering him simultaneously allegoria, exemplum and locis.

Another vivid example of the many different uses of visual metaphors is presented in the chapter dedicated to San Bernardino da Siena's public speeches. Bernardino of Siena was a Franciscan friar who lived in Italy between 1380 and 1444. His popular preaching made him famous during his own lifetime, although it was frequently directed against, sorcery, gambling, infanticide, usury, and others more sensible issues likes witchcraft, sodomy, homosexuality and judaism. Besides its moral authority, Bernardino is often described as a skilled kind of showman, aware of all the tricks used to capture and hold people's attention while competing for audience in a public square.

Lina Bolzoni suggests a classification for Bernardino's use of visual metaphors. Images were frequently used as an implicit or explicit index for the different arguments used along a preach or for the different topics covered in a cycle of speeches. For instance, images like trees, wheals or a a six-winged seraphim where regularly used as a starting point for diagrams that enumerates, and allows to recall, long list of items like christian theological virtues or deadly sins. So it was quite common, in a Bernardino's speech, to listen the equivalent of a table of contents slide, in a contemporary power point presentation, as a description of a familiar form labeled with the main presentation's index.

Another common use was to adopt an image as an illustrations, by evoking some of the (not so abundant) items belonging to the social visual repertory, mostly made by paintings and frescos exposed nearby in public spaces.

Bernardino was also especially talented in creating new visual metaphors by suggesting unconventional synesthetic associations. One of them allows him to use a rook (Corvus frugilegus) as a symbol for procrastination by associating the cry of the 
bird: "Cra Cra Cra ..." with the latin expression for tomorrow "Cras" (as in the english etymology of "pro-cras-tination").

As a mix of the two previous categories, by creating new unorthodox interpretations of existing and recognized images Bernardino has pioneered what we may define today as culture jamming.

And finally, he creates a new iconography - acting as a sort of art director - by reintroducing an updated version of the "JHS" monogram, as support for an ars combinatoria of variable meanings. Bernardino biography is still associated with this christogram, later adopted by religious congregation of the "Society of Jesus" (Jesuits), that becomes part of his own iconography as a Saint.

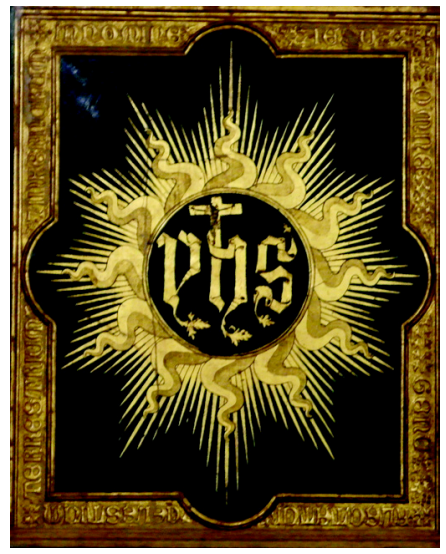

Fig. 2. The YHS monogram Di Laboratorio sf - Opera propria, CC BY-SA 4.0,

The iota-eta-sigma monogram IH $\Sigma$ (from greek IH $\Sigma O Y \Sigma$ : Jesus) was already in use

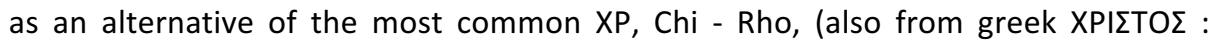
Christus) symbol. IHS, JHS or YHS are all different latin translations for IH $\Sigma$ - most of them can also be read as an acronymous i.e. Jesus Hominum Salvator, or In Hoc Signo, among many others possible meanings. Bernardino's version presents the monogram on the top of a golden blazing sun - with 12 mayor sunbeams and others 144 smaller ones - over a blue background.

This kind of new heraldic-like visual identity for the christian community was also intended as a possible alternative to displace both popular pagan symbols and seals of political factions, like the Guelphs and Ghibellines, from public spaces.

If for one side the YHS monogram can be used, as a whole, as a sign for christianity - on the other side, every single elements offers Bernardino a huge repository of visual references for a limitless combinations of meanings. Consider for instance the letter " $h$ " - drawn in the monogram with an added horizontal stroke as in a cross - in one of his speech, Bernardino invite his audience to associate the letter with the "Holy Spirit" - being "yhs" the trinity - because its curved shapes refers to a pregnant woman (who get pregnant by the HS), because its a silent letter 
and its pronounced just by a breath of air ... because is the 8th letter of the alphabet ... and so on. Bernardino mixed up text and images and used without distinction letters as shapes - and viceversa - in its descriptions that leads to new cultural conventions.

Observed from our point of view, he was able to pack several layers of moral and religious meanings into every single item of the web of images he call forth during its public preaches.

\section{Evolving concepts}

Both, scientists and mystics, shares a common ability for understanding something even before being able to see it.

Our task, as communication designers, is different; most of the times we are asked to convey a message about topics that are already acknowledged. In order to do so, we also pack layers of informations and meaning into visual devices and we expect our audience to be able to move from perception to cognition, without any other external help, and to create by themselves new associations in the network of their ideas and to fix them in a memorable form.

Sometimes this schematic representation behave almost like a real model, as in the periodic table of the chemical elements devised by Dmitri Mendeleev in 1869, that contemplates correctly the position, and therefore the properties, of still unknown elements. Most of the time what we outline are just visual metaphors of the real process.

Visual literacy consists in a set of representation skills, mainly built on empirical knowledge and observation, that has been recently enhanced by several contributions from others disciplines, both from social and natural science.

What we discovered about the physiology of perception mostly confirmed what was previously empirically observed. We have always been aware of optical illusions and, generally speaking, we know that our five senses sometimes lead to weird perceptions. But since we know how represent spaces using perspective, we are also able to produce astonishing anamorphic effects, as in "The Ambassadors" by Hans Holbein the Younger (1533). The same happens with the "Hermann Grid", an optical illusion, noticed by Ludimar Hermann in 1870, we can now explore and easily recreate thanks to what we know about saccade and eye movements. 

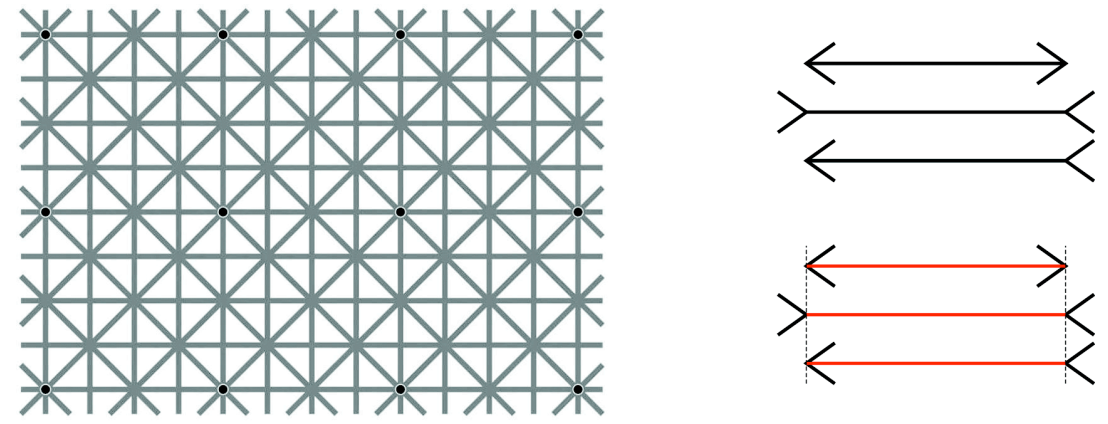

Fig. 3. The Hermann Grid and other optical illusion,

Behind our eyes, even our brain sometime gives us some false impressions. Nowadays, thanks to the "Dual process" theories of cognition (DPT), we're also aware of the existence of cognitive illusions. DPT have been around for a long time but they become popular only recently, thanks to Daniel Kahneman's best seller "Thinking fast and slow".

According to this theory, our cognitive processes are managed by two systems. System 1 produces the fast, intuitive reactions and instantaneous decisions that govern most of our lives while System 2 is the deliberate type of thinking involved in focus, deliberation, reasoning or analysis - such as calculating a complex math problem, exercising self-control, or performing a demanding physical task.

From this perspective, the path from perception to cognition rely on our ability to create compelling sensible images, suitable to be stored by System 2 in order to be easily retrieved by System 1 when needed - as Simone da Cascina and Bernardino da Siena empirically observed.

Even intuitions are not naturals ideas, they are heavily influenced by our cultural conventions and by the authors we familiar with. Carlo Rovelli (2017) gives us a very clear example of this process comparing our natural perception of "time" with the evolution of this concept in contemporary physics.

Time is frequently represented as a uniform linear variable on diagrams and timelines. This linear metaphor is what we have been told at school and is still the way time is conceived in classical mechanics. Now, if you think about our personal perception of time its everything but uniform. We live minutes that lasts for hours, days that rush and never ending seasons.

Physicist told us that time was linear and now they are almost sure that it is not longer true - at leat at certain scales of the matter. At the same time they invite us to understand the world by studying changes rather than things.

As in the past, communication it's essentially a matter of arranging clusters of ideas, in a way they can be easily retrieved, along a transmedia narrative; it requires a solid conceptual background and cultural mediation abilities, as well as our specific visual empirical knowledge. 


\section{References}

Anceschi, G. (1992). L'oggetto della raffigurazione. Milano: Etaslibri.

Bolzoni, L. (2004). The web of images: Vernacular preaching from its origins to St Bernardino da Siena. Aldershot: Ashgate.

Kahneman, D. (2015). Thinking, fast and slow. New York: Farrar, Straus and Giroux.

Neurath, M., \& Kinross, R. (2009). The transformer: Principles of making isotype charts. London: Hyphen.

Ong, W. J., \& Hartley, J. (2002 - 2013). Orality and literacy: The technologizing of the word. London: Routledge, Taylor \& Francis Group.

Perondi, L. (2012). Sinsemie: Scritture nello spazio. Viterbo: Stampa alternativa/ Nuovi equilibri.

Rovelli, C. (2017). L'ordine del tempo. Milano: Adelphi. 